Now, it is clear that our 'moment of conscious awareness' cannot affect other beings. We do not perceive one another's conscious states; and if we consisted only of what consciously appears, we should be imperceptible to one another. And if things consisted in the awareness of a supreme intelligence, they would also be imperceptible. These considerations give proof of the existence of a perceptibly revealed sphere of extra conscious existents, and the characteristics of our percepts symbolically represent these. Now, the author asks whether these characteristics of our bodily organism do not give us information regarding the integration of experience. There is the strongest evidence, the author claims, that conscious states are the outcome of brain activity. He cites in proof of this the dependence of special conscious states on special portions of the brain; also the fact that physiological psychology presupposes that 'sense-stimulating' and 'sense-stimulated' agents exist; that the former affect the latter, arousing percepts, and that modifications of the stimuli are followed by modifications of brain activity and then of consciousness. The author reaches the conclusion that "the specific activities of extra-conscious existents stimulate in definite ways the organic sensibility of our own entire conscious being. This specifically attained action and reaction it is which gives rise to the corresponding conscious states." "Consciousness, emerging thus solely under the functional activity of what is perceptually realized as brain structure, seems to be, therefore, exclusively an outcome of it." In the remainder of the article, which lack of space forbids us to outline, the author seeks to show how, by the same organic process in a progressive development, nerve structure has become integrated, accompanied by a corresponding integration of consciousness.

C. W. HODGE.

\title{
SOCIAL PSYCHOLOGY.
}

(x) L'Anné sociologique, 1894. M. LApIE. Revue de Metaphysique ef de Morate. May, 1895.

(2) La Logique sociale. G. TARde. Paris, Alcan, 1895. Pp. XIV + 464.

Lapie claims that the general characteristic of sociological discussion during the past year is an increasing tendency to emphasize the psychological factors in history and the psychological, as contrasted with the biological, point of view for studying and explaining social facts. This finds illustration (a) in the growing dissatisfaction with the definition of society as an organism. Tarde urges that the 
proper analogue is not an organism in general but a particular organ, the brain. Pioger (La vie sociale, la morale, et le progris) would give the specific difference by calling it a social orgänism. Novicow (Les gaspillages des societtes modernes) maintains that societies are rather to be interpreted as etres spirituels. They are groups of ideas and sentiments. (b) The psychological tendency is seen in various definitions of what constitutes a sociological fact. Durkheim (see this Review for May, 1895 ,) specifies a certain class of psychical facts, viz., those due to constraint. Lacombe (De l'histoire considerée comme science) regards as social those events which are either causes or effects of institutions. Lapie would correct this by pointing out that any idea becomes a social fact as soon as it is transmitted and so finds an echo in the consciousness of others. Tarde considers desires, and beliefs, if imitated, to be the central theme for social study. (c) The causes for social facts are to be sought in psychology. Le Bon (Les lois psychologiques de l'Evolution des peuples) holds that the character creates the destiny of a people. Novicow and Lacombe maintain explicitly that social facts are explained psychologically and not otherwise-'wants act in history,' says the latter, 'not as biologically real but as felt solicitations' (Cf. Ward's The Psychic Factor). Durkheim is the most important objector to the principle of seeking psychological explanation, urging that the cause of a social fact can be only a social fact. I think, however, that the apparent opposition is due to the differing conceptions of the explanation sought. We explain by pointing out the preceding fact, or by analyzing the given fact into its elements (psychological processes). Each has its place.

M. Tarde's work supplements his preceding studies (Lois de l'imitation, etc.), and, as is indicated by its title, is a striking example of the present movement in French sociology traced by Lapie. Imitation is not the sole social fact. It is only the social memory, and memory while the foundation is not the edifice. The object of the book is 'to show the judgment and will at work in society,' to study the variations and inter-relations of beliefs and desires. As Kant's logic asked, 'How is knowledge possible?' so social logic asks, 'How is society possible?' and as Kant discovered certain categories necessary for the individual, so there are essentials for the possibility of society,- ' permanent, necessary conditions of its more or less stable equilibrium.' These are either (a) logical, viz., language and the deity, or (b) teleological, good and evil. As space-time and matter-force are concepts for harmonizing sensations for the individual, so language is a medium for harmonizing perceptions, and the 
deity for harmonizing thoughts and wills in society. Society began when the judgments and wills of individuals came consciously into contact, in agreement or discord, and there resulted a co-ordination of ideas and tendencies of the primitive family, -religion and domestic government. To understand the social processes we need then first a study of the laws which govern the conflict or coalescence of beliefs of varying degrees of strength. This yields quite a different classification of judgments from that of the traditional logic and a correspondingly different syllogism; and the conditions here analyzed are those most frequent in daily life and even scientific induction, for here the process is not one of drawing an inference from premises of equal certainty, but of a cumulative series of proofs resulting in increasing probability and stronger belief.

After a very suggestive treatment of this new logic of beliefs in his first chapter the author goes on to elaborate his doctrine of the social categories and to present analogies, some fruitful, some rather far-fetched (e.g., when glory as social phenomenon is compared to self-consciousness) between the social and the individualistic phases of consciousness. The application of the principles developed to language, religion, the sentiments of the heart, political economy and art occupies the second half of the work. The role of imitation in all these departments is emphasized, but perhaps as a result in part of the criticisms on his earlier work, it is not over-worked, and the psychologist may find much valuable material in these chapters.

UnIV. of ChICAGo.

J. H. Turs.

\section{NEUROLOGY.}

Die Localisationstheoric Angewandt auf psychologische Probleme. Beispiel : Warum sind wir "zerstreut"? G. HrRTr. Einleitung von Ludwig Edinger. Zweite vermehrte Auflage. München, Hirth, 1895. Pp. XXIV + II2.

The extraordinary progress of minute histology of the nervous system within the last decade could not help arousing the interest of many speculative minds. While numerous attempts are made to fill the wide gap between the scanty data of localisation of motor and sensory areas of the cerebral cortex, and a possible localisation of the correlates of mental activity, it must become exceedingly difficult for one not following the strictly anatomical literature, to find out where the well established facts are at an end and where speculation looses touch with actual observation. Many papers are indeed so confusing that the present little work can be considered a very 